\title{
Pressurized intraperitoneal aerosol chemotherapy for recurrent ovarian, fallopian or primary peritoneal cancer with peritoneal carcinomatosis: a narrative review
}

\author{
Soohyun Oh", Haerin Paik", Soo Jin Park, Eun Ji Lee, Hee Seung Kim \\ Department of Obstetrics and Gynecology, Seoul National University College of Medicine, Seoul, Korea \\ Contributions: (I) Conception and design: S Oh, HS Kim; (II) Administrative support: HS Kim; (III) Provision of study materials or patients: HS Kim; \\ (IV) Collection and assembly of data: S Oh, H Paik, HS Kim; (V) Data analysis and interpretation: All authors; (VI) Manuscript writing: All authors; \\ (VII) Final approval of manuscript: All authors. \\ \#These authors contributed equally to this work. \\ Correspondence to: Hee Seung Kim, MD, PhD. Department of Obstetrics and Gynecology, Seoul National University College of Medicine, 101 \\ Daehak-Ro Jongno-Gu, Seoul 110-744, Korea. Email: bboddi0311@gmail.com.
}

\begin{abstract}
For recurrent ovarian, fallopian or primary peritoneal cancer with peritoneal carcinomatosis (PC), it is challenging to resect tumors completely or to get complete remission by intravenous (IV) chemotherapy, and many patients show the resistance to various chemotherapeutic agents for IV chemotherapy ultimately. As an alternative, pressurized intraperitoneal aerosol chemotherapy (PIPAC) has been introduced for treating the disease, which delivers chemotherapeutic agents as an aerosol form while maintaining high intraperitoneal (IP) pressure. Based on preclinical studies, PIPAC showed better penetration depth and distribution of drugs into the peritoneum in comparison to conventional IP chemotherapy. Tumor regression on histology and peritoneal carcinomatosis index (PCI) has also been shown in relevant studies. In addition, most of the PIPAC procedures were completed successfully with acceptable toxicity due to the use of a low dose of chemotherapeutic agents. For considering these advantages of PIPAC, we review the current status of PIPAC for treating recurrent ovarian, fallopian or primary peritoneal cancer through literature review.
\end{abstract}

Keywords: Pressurized; intraperitoneal (IP); aerosol; chemotherapy; ovarian; fallopian; peritoneal; cancer

Submitted Mar 06, 2020. Accepted for publication Aug 05, 2020.

doi: $10.21037 / g s-2019$-ursoc-12

View this article at: http://dx.doi.org/10.21037/gs-2019-ursoc-12

\section{Introduction}

Among malignant tumors in the pelvic cavity, the most common cancer is colorectal and ovarian cancers, which show disease recurrence with peritoneal carcinomatosis (PC) in $20-60 \%$ of colorectal cancer and $80 \%$ of ovarian cancers $(1,2)$. Furthermore, the prognosis is quite dismal, regarding the fact that survival is less than 20 months despite the treatment of PC (3). For improving the prognosis, especially in ovarian, fallopian or peritoneal cancer, various types of intraperitoneal (IP) chemotherapy have been introduced for maximizing the effect of chemotherapeutic agents by direct administration of them into the abdominal cavity. Although IP chemotherapy showed better survival than intravenous (IV) chemotherapy, about $50 \%$ of patients did not receive whole cycles of IP chemotherapy due to relevant complications, which still hinders the introduction of IP chemotherapy in the clinical setting (4). We present the following article in accordance with the Narrative review reporting checklist (available at http://dx.doi.org/10.21037/ gs-2019-ursoc-12).

To overcome this limitation, hyperthermic intraperitoneal chemotherapy (HIPEC) has been introduced, which show the effect by direct penetration of chemotherapeutic agents into microscopic tumor after cytoreductive surgery and hyperthermia to enhance the cytotoxic effect $(5,6)$. Nonetheless, HIPEC has little effect 
on gross tumor due to poor penetration depth of $1-5 \mathrm{~mm}$, and it is difficult to distribute chemotherapeutic agents evenly because of the cylindrical structure of the abdominal cavity. In addition, the toxicity is still burdensome because grade 3 or 4 renal and hepatic toxicity is found in $23 \%$ of patients, and treatment-related death is expected in $7 \%$ of them (7).

Since November 2011, pressurized intraperitoneal aerosol chemotherapy (PIPAC) has been implemented for treating PC, mainly in European countries. In PIPAC, a low dose of chemotherapeutic agents is distributed as aerosols into the abdominal cavity under high abdominal pressure produced by the laparoscopic system, which increases the depth of penetration, and reduces relevant systemic toxicities (8). Even though PIPAC is considered a feasible treatment option, there is still a lack of highquality evidence that precludes the application of PIPAC as a standard of care. To assess whether there is any potential that can be clinically introduced, we reviewed the procedure, efficacy and safety of PIPAC for treating recurrent ovarian, fallopian or primary peritoneal cancer with PC in the current study.

\section{Procedure}

The standard procedure for PIPAC is as follows. First, under general anesthesia, two trocars are inserted after the insufflation of $\mathrm{CO}_{2}$ gas, and capnoperitoneum is maintained at the abdominal pressure of $12 \mathrm{mmHg}$. The nebulizer and laparoscope were inserted via each trocar, and the third trocar can be needed additionally for technically difficult cases (9-11). Thereafter, explorative laparoscopy is performed to determine the extent of the disease by using the peritoneal carcinomatosis index (PCI) score (12), and tissue biopsy, if needed, is performed at suspicious lesions. Then, a nebulizer (MIP ${ }^{\circledR}$, Reger Medizintechnik, Germany) is connected to a high-pressure injector (Injektron $82 \mathrm{M}$, MedTron, Germany) via a high-pressure connecting line, and then it is inserted into the abdominal cavity through the trocar. Chemotherapeutic agents are administered in the form of aerosol by the nebulizer at a flow rate of $30 \mathrm{~mL} / \mathrm{min}$ under the maximum upstream pressure or $200 \mathrm{psi}(9,13,14)$.

After the injection of a pressurized aerosol, capnoperitoneum is maintained as a closed system at $37{ }^{\circ} \mathrm{C}$ for 30 minutes, and then the toxic aerosol is eliminated through a closed waste system using microparticle filters. Under the protection of laminar airflow, aerosols are disposed to the waste-air management system of the hospital (11).

Up to now, PIPAC is usually performed in the inpatient setting where most patients discharge on postoperative two or three days $(3,15)$. However, PIPAC is also being applied in the outpatient setting because most of the adverse events have been self-limiting and mild, with no difference in them after PIPAC in the inpatient setting $(16,17)$.

\section{Preclinical efficacy}

In comparison with conventional IP chemotherapy, PIPAC yields better distribution within the abdominal cavity and superior penetration into the peritoneum tissue (17). Moreover, the depth of penetration of chemotherapeutic agents has been shown to be improved by PIPAC when compared to lavage IP chemotherapy, suggesting that aerosolized drugs can be penetrated up to $1 \mathrm{~mm}$ into the peritoneum (18). However, the heterogeneous distribution of agents is still the major limitation to be improved. In ex vivo studies, the depth of doxorubicin was higher in tissues directly exposed to the nebulizer than in tissues located in the opposite top or sidewall after PIPAC, showing the uneven distribution and depth of penetration $(19,20)$. The reason is that $>97.5 \mathrm{vol} \%$ of the aerosolized liquid may be delivered as droplets with $>3 \mu \mathrm{m}$ in diameter, which are primarily deposited on the surface beneath the nebulizer (21). Thus, the change of spray direction by rotation of the nebulizer can be considered to overcome this limitation (22).

\section{Clinical efficacy}

In humans, the depth of penetration of doxorubicin showed up to $500 \mu \mathrm{m}$, and its concentration in tissues was 200 times higher than that in blood, which suggested why chemotherapeutic agents resistant to tumors can be effective when applied in PIPAC (13). Table 1 depicts ten relevant studies where the effect of PIPAC was investigated based on this hypothesis. Among 376 patients in nine relevant studies (9,13,15,23-28), 200 had recurrent ovarian, fallopian or primary peritoneal cancer with PC. Among them, six studies included mainly the patients with platinum-resistant recurrent disease who received at least one line of previous IV chemotherapy (9,23-27), whereas there is a lack of a history of previous treatment before PIPAC in the other three studies. In most studies, the efficacy of PIPAC has been evaluated for patients treated with two or more cycles of PIPAC using doxorubicin and cisplatin. As a result, PCI 
Table 1 Results of clinical studies related with pressurized intraperitoneal aerosol chemotherapy (PIPAC) for recurrent ovarian, fallopian or primary peritoneal cancer with peritoneal carcinomatosis

\begin{tabular}{|c|c|c|c|c|c|c|c|c|c|c|c|c|}
\hline \multirow[b]{2}{*}{ Authors } & \multirow[b]{2}{*}{ Design } & \multirow[b]{2}{*}{ No. of patients } & \multirow[b]{2}{*}{$\begin{array}{l}\text { No. of cycles } \\
\text { of PIPAC }\end{array}$} & \multicolumn{2}{|c|}{ No. of cycles $(\mathrm{n} / \mathrm{N}, \%)$} & \multirow[b]{2}{*}{ Regimen } & \multicolumn{5}{|c|}{ Efficacy analysis } & \multirow{2}{*}{$\begin{array}{l}\text { Overall survival } \\
\text { (months) }\end{array}$} \\
\hline & & & & $\geq 2$ cycles & $\geq 3$ cycles & & $\begin{array}{l}\text { Improvement } \\
\text { of PCl }(\mathrm{n} / \mathrm{N}, \%)\end{array}$ & $\begin{array}{l}\text { Pathologic } \\
\text { response (n/N, \%) }\end{array}$ & ORR (n/N, \%) & $\mathrm{DCR}(\mathrm{n} / \mathrm{N}, \%)$ & Other criteria $(\mathrm{n} / \mathrm{N}, \%)$ & \\
\hline Tempfer 2014 (9) & Retrospective & $\begin{array}{l}\text { Total ( }(n=21) \text { : OC }(n=16) ; \\
\text { PC }(n=4) ; \text { FC }(n=1)\end{array}$ & 34 & $8 / 18^{*}(44.4)$ & 4/18 (22.2) & C, D & - & $6 / 8(75.0)$ & 3/8 (37.5) & $6 / 8(75.0)$ & - & 14.5 (mean) \\
\hline Solass 2014 (13) & Retrospective & Total $(n=3): O C(n=1)$ & 11 & $3 / 3^{*}(100)$ & $2 / 3(66.7)$ & $C, D$ & - & $2 / 3(66.7)$ & $2 / 3(66.7)$ & $3 / 3(100)$ & - & 9.4 (mean) \\
\hline Giger-Pabst 2015 (23) & Retrospective & $\mathrm{OC}(\mathrm{n}=1)$ & 8 & 1/1 (100) & 1/1 (100) & $C, D$ & $1 / 1(100)$ & $1 / 1(100)$ & - & 1/1 (100) & - & - \\
\hline Tempfer 2015 (24) & Phase 2 & $\begin{array}{l}\text { Total (n=64): OC }(n=47) ; \\
\text { PC }(n=4) ; \mathrm{FC}(n=2)\end{array}$ & 130 & 43/53(81) & $34 / 53^{*}(64.2)$ & C, D & PP: $26 / 34$ (76.5) & $\begin{array}{l}\text { ITT: 33/53 (62.3); } \\
\text { PP: 26/34 (76.5) }\end{array}$ & $\begin{array}{l}\text { ITT: } 3 / 53(5.7) ; \\
\text { PP: } 1 / 31(3.2)\end{array}$ & $\begin{array}{l}\text { ITT: } 33 / 53(62.3) ; \\
\text { PP: } 16 / 31 \text { (51.6) }\end{array}$ & - & $\begin{array}{l}\text { ITT: } 10.8 \text { (mean); } \\
\text { PP: } 13.3 \text { (mean) }\end{array}$ \\
\hline Tempfer 2015 (25) & Retrospective & $\begin{array}{l}\text { Total ( }(n=99): \text { OC }(n=84) ; \\
\text { PC (n=6); FC }(n=1)\end{array}$ & 252 & $50 / 82^{\star}(61.0)$ & 34/82 (41.5) & C, D & $32 / 50(64.0)$ & $38 / 50(76.0)$ & - & - & $\begin{array}{c}\text { Mean ascites reduction rate } \\
(78.1)(P=0.02)\end{array}$ & 14.1 (mean) \\
\hline Tempfer 2017 (26) & Retrospective & $\mathrm{OC}(\mathrm{n}=1)$ & 13 & $1 / 1(100)$ & 1/1 (100) & $C, D$ & $1 / 1(100)$ & $1 / 1(100)$ & - & $1 / 1(100)$ & - & - \\
\hline Kurtz 2018 (16) & Retrospective & Total $(n=71): 0 C(n=6)$ & 142 & $39 / 63^{*}(61.9)$ & 20/63 (31.7) & $C, D, O$ & - & $24 / 36(66.7) ; 10 / 36^{\dagger}(27.8)$ & - & - & $\begin{array}{l}\text { Significant ascites reduction } \\
\text { (in initial pts. with ascites } \\
>300 \mathrm{~mL})(\mathrm{P}=0.03)\end{array}$ & 11.8 (median) \\
\hline Tempfer 2018 (27) & Phase I & $\begin{array}{l}\text { Total }(n=15): \text { OC }(n=13) ; \\
\text { FC }(n=1) ; \operatorname{PC}(n=1)\end{array}$ & 34 & $11 / 15^{*}(73.3)$ & $8 / 15(53.3)$ & C, D & - & $7 / 11$ (63.6) & - & - & - & - \\
\hline Sgarbura 2019 (28) & Retrospective & Total $(n=101): \mathrm{OC}(n=5)$ & 251 & $65 / 101(64.3)$ & $48 / 101(47.5)$ & 0 & - & - & - & - & $\begin{array}{l}\text { Improved symptom: 50/101 } \\
\text { (49.5) }\end{array}$ & - \\
\hline
\end{tabular}

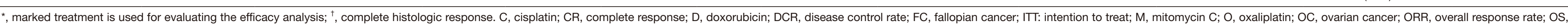
overall survival; PC, primary peritoneal cancer; PCI, peritoneal carcinomatosis index; PFS, progression-free survival; PP: per protocol; PR, partial response; SD, stable disease. 
improvement and pathologic response were observed in $64-100 \%$ and $62.3-100 \%$, respectively. Moreover, overall response rate, including complete response (CR) and partial response (PR), disease control rate including $\mathrm{CR}, \mathrm{PR}$, and stable disease (SD), were found in $3.2-66.7 \%$ and $51.6-$ $100 \%$, respectively. In terms of survival, median, and mean values of overall survival ranged from 9.4 to 14.5 months.

\section{Accessibility, mortality, and toxicity}

For evaluating the accessibility, treatment-related mortality, and toxicity of PIPAC in patients with ovarian, fallopian or primary peritoneal cancer, we found 14 relevant studies $(3,9,10,13-15,23-30)$. In terms of the accessibility of PIPAC, it was sometimes impossible due to laparoscopic non-access by postoperative adhesion or inability to create a sufficient working chamber. In clinical setting, non-access rates range from $0-17 \%(3,7,9,10,13-15,23-25,27)$. In terms of treatment-related mortality, up to $6.8 \%$ of patients have been reported to have the risk. Moreover, the rate of grade 3 to 5 toxicity was shown up to $23.8 \%$. In detail, grade 3,4 and 5 toxicities were observed in up to $17.2 \%, 33.3 \%$ and $2.3 \%$, respectively (Table 2$)(22,27)$.

\section{Quality of life}

In a palliative setting, PIPAC is known to maintain or improve the quality of life for patients with PC. In patients with end-stage PC, PIPAC has been shown to improve the quality of life by up to $89 \%$ (30). In particular, gastrointestinal dysfunction such as nausea, vomiting, loss of appetite, obstipation, and diarrhea did not worsen and remained relatively constant over repetitive procedures. Moreover, no deterioration of physical, emotional, and cognitive functions has been reported (3), and nutritional status has also been improved during PIPAC, which suggests that the role of PIPA in palliative settings may maintain or improve the quality of life without deterioration (31).

\section{Electronic precipitation PIPAC (ePIPAC)}

ePIPAC is a novel technique that utilizes charged therapeutic aerosols to increase tissue uptake, which has been reported to need only one minute for diffusing aerosols compared to conventional PIPAC requiring 30 minutes (32). In the previous study related to ePIPAC, a total of 48 patients with PC were included for ePIPAC, among whom 20 (41.7\%) did not complete three cycles of ePIPAC, mainly due to disease progression. Among the remaining 28 patients treated with three cycles of ePIPAC, 11 (39.3\%), 2 (7.1\%) and 15 (53.6\%) showed an overall response, stable disease, and progressive disease, respectively, and relevant toxicities were acceptable without grade 4 or 5 adverse events, suggesting that ePIPAC may be safe and tolerable (33). However, further relevant studies should be needed for evaluating the improved effect of ePIPAC compared to conventional PIPAC due to a lack of evidence (32).

\section{Occupational safety}

Delivering chemotherapeutic agents as aerosols have raised concerns about the potential risk of exposure to health care workers. To assess this issue, occupational safety has been evaluated in an operating room with laminar airflow (34). In this study, doxorubicin and cisplatin were administered during PIPAC with a $10 \%$ dose of agents used for IV chemotherapy. Trocars were secured with an air-tight intraabdominal balloon for preventing leakage of agents, and the gas in the abdomen was disposed through an aerosol or smoke filter to the hospital's waste-air system at the end of the procedure. All the procedures were remote controlled. Air was sampled on a cellulose nitrate filter, which was evaluated toxicologically. As a result, there was no leakage of cisplatin related to PIPAC, and the risk of skin contamination was expected to be minimal due to the closed system of PIPAC. Moreover, it was suggested to be dealt with wearing special protective gloves and glasses if air leakage was identified. However, further studies are required to prove the occupational safety of other chemotherapeutic agents.

\section{Ongoing trials}

When we searched ongoing clinical trials assessing PIPAC for ovarian, fallopian or primary peritoneal cancer in the US National Institutes of Health ClinicalTrials.gov registry, we found three among 15 relevant trials. The first trial is an open-label, single-arm phase I-II clinical trial (NCT 02735928), named "Pressurized Intraperitoneal Aerosol Chemotherapy Applied to Platinum-Resistant Recurrence of Ovarian Tumor (PARROT)", where patients with first or second recurrent platinum-resistant ovarian cancer undergo PIPAC procedure using cisplatin and doxorubicin. The primary endpoint is to determine the clinical benefit rate of 


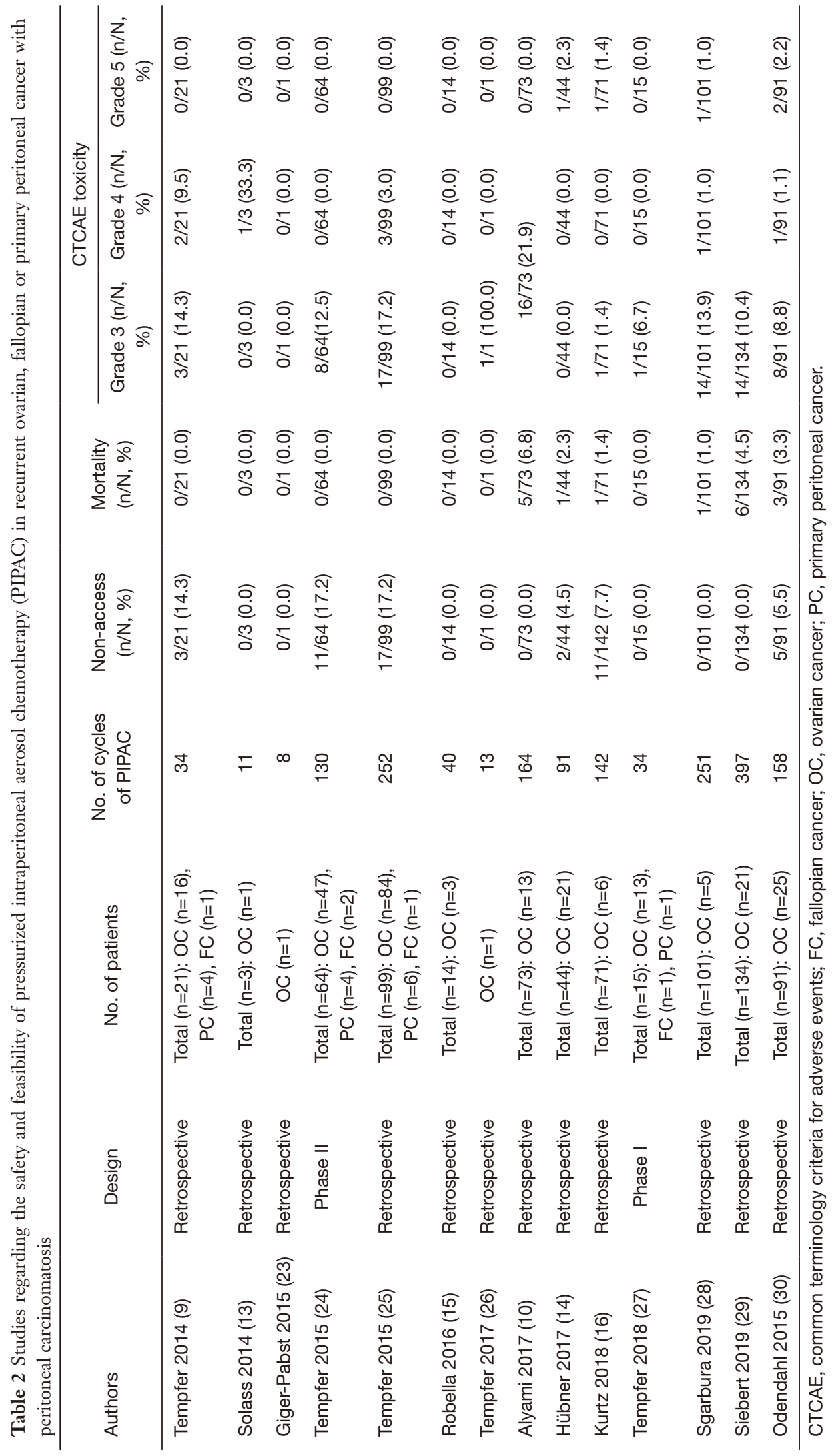


PIPAC, and the secondary endpoints are the median time to progression after three cycles of PIPAC, PCI assessed by laparoscopy, the degree of histological regression assessed by pathological review of repeated peritoneal biopsies, the proportion of women with a reduction of serum CA-125 of at least $50 \%$ after PIPAC, and evaluation of the quality of life. This trial has been started in January 2016, which is estimated to enroll 50 patients.

The second trial is a phase study with the title, "Treatment of Peritoneal Carcinomatosis With Pressurized IntraPeritoneal Aerosol Chemotherapy-The PIPACOPC2 Trial (NCT03287375)". In this trial, A total of 137 patients with gastrointestinal, ovarian or peritoneal cancer will be enrolled, among whom those with ovarian cancer must be platinum-resistant. The primary endpoint is the rate of objective tumor response evaluated by the Peritoneal Regression Grading Score during PIPAC, and the secondary endpoints are the evaluation of the quality of life, and detection of PC by magnetic resonance image compared to laparoscopic during PIPAC.

The third trial is a non-randomized clinical trial in a single center (NCT02604784), which is entitled "Feasibility, Efficacy, and Safety of Pressurized IntraPeritoneal Air-flow Chemotherapy (PIPAC) with Oxaliplatin, Cisplatin, and Doxorubicin in Patients With Peritoneal Carcinomatosis From Colorectal, Ovarian, Gastric Cancers and Primary Tumors of the Peritoneum: An Open-label, Two-arms, Phase I-II Clinical trial-PI-CAp". Among 105 patients required in this trial, those with indications for standard systemic chemotherapy are assigned to a cohort, whereas the others are designated to cohort B for PIPAC using doxorubicin, cisplatin, and oxaliplatin with a dose-escalating design. The primary endpoint is overall response rate, and the secondary endpoints include overall survival, degree of histological regression, the median time to progression, measurement of clinical tumor response using FDGpositron emission tomography (PET), and changes of PCI scores (35).

\section{Conclusions}

PIPAC may be feasible and safe in ovarian, fallopian or primary peritoneal cancer with PC. The maintenance of a high concentration of chemotherapeutic agents in tissue by repetitive procedures may contribute to the effect of PIPAC, in particular, in patients with platinum-resistant recurrent disease. Since we estimated the response rat from heterogeneous population and overall survival from limited values of survival in previous studies, there are still limitations for clinical application of PIPAC in the patients because of a relative lack of relevant studies that show the effect and safety and suggest other agents with occupational safety. In the future, it is expected that clinical applications of PIPAC will increase with the accumulation of relevant research results for ovarian, fallopian or primary peritoneal cancer.

\section{Acknowledgments}

We deeply appreciate to Dalim Corp. for the financial support.

Funding: This work was supported by grants from Seoul National University (No. 800-20170249, 800-20180201, 800-20190437) and Seoul National University Hospital (No. 0620173250). Moreover, this study was supported by a grant of the Korea Health Technology R\&D Project through the Korea Health Industry Development Institute (KHIDI), funded by the Ministry of Health \& Welfare, Republic of Korea (No. HI19C0664).

\section{Footnote}

Provenance and Peer Review: This article was commissioned by the Guest Editors (Sang Yoon Park, Jae Weon Kim) for the series "Ultra-Radical Surgery in Ovarian Cancer: Surgical Techniques for Gynecologic Oncologist" published in Gland Surgery. The article was sent for external peer review organized by the Guest Editors and the editorial office.

Reporting Checklist: The authors have completed the Narrative review reporting checklist. Available at http:// dx. doi. org/10. 21037/gs-2019-ursoc-12

Conflicts of Interest: The authors have completed the ICMJE uniform disclosure form (available at http://dx. doi. org/10. 21037/gs-2019-ursoc-12). The series "UltraRadical Surgery in Ovarian Cancer: Surgical Techniques for Gynecologic Oncologist" was commissioned by the editorial office without any funding or sponsorship. HSK serves as an unpaid editorial board member of Gland Surgery from Aug 2019 to Jul 2021. The authors have no other conflicts of interest to declare.

Ethical Statement: The authors are accountable for all aspects of the work in ensuring that questions related 
to the accuracy or integrity of any part of the work are appropriately investigated and resolved.

Open Access Statement: This is an Open Access article distributed in accordance with the Creative Commons Attribution-NonCommercial-NoDerivs 4.0 International License (CC BY-NC-ND 4.0), which permits the noncommercial replication and distribution of the article with the strict proviso that no changes or edits are made and the original work is properly cited (including links to both the formal publication through the relevant DOI and the license). See: https://creativecommons.org/licenses/by-nc-nd/4.0/.

\section{References}

1. Heintz A, Odicino F, Maisonneuve P, et al. Carcinoma of the Ovary. Int J Gynaecol Obstet 2006;95 Suppl 1:S161-92.

2. Quere P, Facy O, Manfredi S, et al. Epidemiology, Management, and Survival of Peritoneal Carcinomatosis from Colorectal Cancer: A Population-Based Study. Dis Colon Rectum 2015;58:743-52.

3. Robella M, Vaira M, De Simone M. Safety and feasibility of pressurized intraperitoneal aerosol chemotherapy (PIPAC) associated with systemic chemotherapy: an innovative approach to treat peritoneal carcinomatosis. World J Surg Oncol 2016;14:128.

4. Armstrong DK, Bundy B, Wenzel L, et al. Intraperitoneal cisplatin and paclitaxel in ovarian cancer. $\mathrm{N}$ Engl J Med 2006;354:34-43.

5. Knox JD, Mitchel RE, Brown DL. Effects of hyperthermia on microtubule organization and cytolytic activity of murine cytotoxic T lymphocytes. Exp Cell Res 1991;194:275-83.

6. Steller MA, Egorin MJ, Trimble EL, et al. A pilot phase I trial of continuous hyperthermic peritoneal perfusion with high-dose carboplatin as primary treatment of patients with small-volume residual ovarian cancer. Cancer Chemother Pharmacol 1999;43:106-14.

7. Tempfer CB, Solass W, Buerkle B, Pressurized intraperitoneal aerosol chemotherapy (PIPAC) with cisplatin and doxorubicin in a woman with pseudomyxoma peritonei: A case report. Gynecol Oncol Rep 2014;10:32-5.

8. Tempfer CB. Pressurized intraperitoneal aerosol chemotherapy as an innovative approach to treat peritoneal carcinomatosis. Med Hypotheses 2015;85:480-4.

9. Tempfer CB, Celik I, Solass W, et al. Activity of Pressurized Intraperitoneal Aerosol Chemotherapy
(PIPAC) with cisplatin and doxorubicin in women with recurrent, platinum-resistant ovarian cancer: preliminary clinical experience. Gynecol Oncol 2014;132:307-11.

10. Alyami M, Gagniere J, Sgarbura O, et al. Multicentric initial experience with the use of the pressurized intraperitoneal aerosol chemotherapy (PIPAC) in the management of unresectable peritoneal carcinomatosis. Eur J Surg Oncol 2017;43:2178-83.

11. Hübner M, Grass F, Teixeira-Farinha H, et al. Pressurized IntraPeritoneal Aerosol Chemotherapy - Practical aspects. Eur J Surg Oncol 2017;43:1102-9.

12. Harmon RL, Sugarbaker PH. Prognostic indicators in peritoneal carcinomatosis from gastrointestinal cancer. Int Semin Surg Oncol 2005;2:3.

13. Solass W, Kerb R, Mürdter T, et al. Intraperitoneal chemotherapy of peritoneal carcinomatosis using pressurized aerosol as an alternative to liquid solution: first evidence for efficacy. Ann Surg Oncol 2014;21:553-9.

14. Hübner M, Farinha HT, Grass F, et al. Feasibility and Safety of Pressurized Intraperitoneal Aerosol Chemotherapy for Peritoneal Carcinomatosis: A Retrospective Cohort Study. Gastroenterol Res Pract 2017;2017:6852749.

15. Kurtz F, Struller F, Horvath P, et al. Feasibility, safety, and efficacy of Pressurized Intraperitoneal Aerosol Chemotherapy (PIPAC) for peritoneal metastasis: a registry study. Gastroenterol Res Pract 2018;2018:2743985.

16. Graversen M, Lundell L, Fristrup C, et al. Pressurized IntraPeritoneal Aerosol Chemotherapy (PIPAC) as an outpatient procedure. Pleura Peritoneum 2018;3:20180128.

17. Solaß W, Hetzel A, Nadiradze G, et al. Description of a novel approach for intraperitoneal drug delivery and the related device. Surg Endosc 2012;26:1849-55.

18. Solass W, Herbette A, Schwarz T, et al. Therapeutic approach of human peritoneal carcinomatosis with Dbait in combination with capnoperitoneum: proof of concept. Surg Endosc 2012;26:847-52.

19. Khosrawipour V, Khosrawipour T, Diaz-Carballo D, et al. Exploring the Spatial Drug Distribution Pattern of Pressurized Intraperitoneal Aerosol Chemotherapy (PIPAC). Ann Surg Oncol 2016;23:1220-4.

20. Khosrawipour V, Khosrawipour T, Falkenstein TA, et al. Evaluating the Effect of Micropump(c) Position, Internal Pressure and Doxorubicin Dosage on Efficacy of Pressurized Intra-peritoneal Aerosol Chemotherapy (PIPAC) in an Ex Vivo Model. Anticancer Res 2016;36:4595-600. 
21. Göhler D, Khosrawipour V, Khosrawipour T, et al. Technical description of the microinjection pump $(\mathrm{MIP}((\mathrm{R})))$ and granulometric characterization of the aerosol applied for pressurized intraperitoneal aerosol chemotherapy (PIPAC). Surg Endosc 2017;31:1778-84.

22. Khosrawipour V, Khosrawipour T, Kern AJ, et al. Distribution pattern and penetration depth of doxorubicin after pressurized intraperitoneal aerosol chemotherapy (PIPAC) in a postmortem swine model. J Cancer Res Clin Oncol 2016;142:2275-80.

23. Giger-Pabst U, Solass W, Buerkle B, et al. Low-dose Pressurized Intraperitoneal Aerosol Chemotherapy (PIPAC) as an Alternative Therapy for Ovarian Cancer in an Octogenarian Patient. Anticancer Res 2015;35:2309-14.

24. Tempfer CB, Winnekendonk G, Solass W, et al.

Pressurized intraperitoneal aerosol chemotherapy in women with recurrent ovarian cancer: a phase 2 study. Gynecol Oncol 2015;137:223-8.

25. Tempfer CB, Rezniczek GA, Ende P, et al. Pressurized Intraperitoneal Aerosol Chemotherapy with Cisplatin and Doxorubicin in Women with Peritoneal Carcinomatosis: A Cohort Study. Anticancer Res 2015;35:6723-9.

26. Tempfer CB, Hartmann F, Hilal Z, et al. Intraperitoneal cisplatin and doxorubicin as maintenance chemotherapy for unresectable ovarian cancer: a case report. BMC Cancer 2017;17:26.

27. Tempfer CB, Giger-Pabst U, Seebacher V, et al. A phase I, single-arm, open-label, dose escalation study of intraperitoneal cisplatin and doxorubicin in patients with recurrent ovarian cancer and peritoneal carcinomatosis. Gynecol Oncol 2018;150:23-30.

28. Sgarbura O, Hübner M, Alyami M, et al. Oxaliplatin use in pressurized intraperitoneal aerosol chemotherapy (PIPAC) is safe and effective: A multicenter study. Eur J Surg Oncol
2019;45:2386-2391.

29. Siebert M, Alyami M, Mercier F, et al. Pressurized intraperitoneal aerosol chemotherapy (PIPAC) in association with systemic chemotherapy and bevacizumab, evaluation of safety and feasibility. A single center comparative study. Eur J Surg Oncol 2019;S07487983(19)30349-X.

30. Odendahl K, Solass W, Demtroder C, et al. Quality of life of patients with end-stage peritoneal metastasis treated with Pressurized IntraPeritoneal Aerosol Chemotherapy (PIPAC). Eur J Surg Oncol 2015;41:1379-85.

31. Hilal Z, Rezniczek GA, Klenke R, et al. Nutritional status, cachexia, and anorexia in women with peritoneal metastasis and intraperitoneal chemotherapy: a longitudinal analysis. J Gynecol Oncol 2017;28:e80.

32. Kakchekeeva T, Demtroder C, Herath NI, et al. In Vivo Feasibility of Electrostatic Precipitation as an Adjunct to Pressurized Intraperitoneal Aerosol Chemotherapy (ePIPAC). Ann Surg Oncol 2016;23:592-8.

33. Willaert W, Van de Sande L, Van Daele E, et al. Safety and preliminary efficacy of electrostatic precipitation during pressurized intraperitoneal aerosol chemotherapy (PIPAC) for unresectable carcinomatosis. Eur J Surg Oncol 2019;45:2302-9.

34. Solass W, Giger-Pabst U, Zieren J, et al. Pressurized intraperitoneal aerosol chemotherapy (PIPAC): occupational health and safety aspects. Ann Surg Oncol 2013;20:3504-11.

35. "ClinicalTrials.gov." Bethesda: Natinoal Library of Medicine (US), Available online: https://clinicaltrials.gov/ ct $2 /$ results? cond=Pressurized+intraperitoneal+aerosol+che motherapy $\&$ term $=\&$ cntry $=\&$ state $=\&$ city $=\&$ dist $=;$ accessed March 2020.
Cite this article as: Oh S, Paik H, Park SJ, Lee EJ, Kim HS. Pressurized intraperitoneal aerosol chemotherapy for recurrent ovarian, fallopian or primary peritoneal cancer with peritoneal carcinomatosis: a narrative review. Gland Surg 2021;10(3):12441251. doi: $10.21037 /$ gs-2019-ursoc-12 